\title{
Электрохимическое осаждение контактных материалов в постростовой технологии фотоэлектрических преобразователей
}

\author{
() А.В. Малевская, Н.Д. Ильинская, Д.А. Малевский, П.В. Покровский \\ Физико-технический институт им. А.Ф. Иофрфе Российской академии наук, \\ 194021 Санкт-Петербург, Россия \\ E-mail: amalevskaya@mail.ioffe.ru
}

Поступила в Редакцию 17 ноября 2021 г.

В окончательной редакции 25 ноября 2021 г.

Принята к публикации 25 ноября 2021 г.

\begin{abstract}
Проведены исследования и моделирование процесса электрохимического наращивания омических контактов при проведении постростовой технологии изготовления фотоэлектрических преобразователей. Разработана технология гальванического осаждения контактной системы $\mathrm{Ag} / \mathrm{Au}$ при вертикальном и горизонтальном расположении гетероструктуры и анода в электролите. Достигнуто увеличение равномерности осаждения контактной системы до величины $\sim 95 \%$ при толщине контактных шин $\sim 5$ мкм на площади гетероструктуры диаметром до $10 \mathrm{~cm}$.
\end{abstract}

Ключевые слова: фотоэлектрические преобразователи, омические контакты, электрохимическое осаждение.

DOI: $10.21883 /$ FTP.2022.03.52127.9774

\section{1. Введение}

Фотоэлектрические преобразователи (ФЭП) солнечного излучения являются основным источником электропитания космических аппаратов и при этом находятся в условиях открытого космического пространства, что обусловливает повышенные требования, предъявляемые к технологии формирования ФЭП в составе солнечных батарей [1-4]. ФЭП должны обладать повышенной стойкостью при работе в экстремальных условиях окружающей среды: в условиях повышенной радиации, при высокой интенсивности солнечного излучении и в условиях значительного перепада температур.

Одним из основных этапов постростовой технологии изготовлении ФЭП является технология формирования омических контактов. Уменьшение удельного переходного контактного сопротивления и увеличение электрической проводимости контактных шин обеспечивает увеличение токосъема с элемента, увеличение рабочей мощности ФЭП и, соответственно, эффективность его работы $[5,6]$. Важным аспектом в технологии формирования омических контактов ФЭП является процесс электрохимического наращивания с использованием контактных материалов, обладающих высокой электропроводностью, а также химической и механической стойкостью к воздействию условий окружающей среды [7].

При разработке контактной системы ФЭП для космического применения площадью до $30 \mathrm{~cm}^{2}$ [8] важным параметром является равномерность толщины омических контактов по площади гетероструктуры, обеспечивающей максимальный токосьем с элемента.

Постростовая технология изготовления ФЭП в данной работе была разработана на основе трехкаскадной гетероструктуры $\mathrm{GaInP} / \mathrm{Ga}(\mathrm{In}) \mathrm{As} / \mathrm{Ge}$, выращенной на германиевой подложке $p$-типа проводимости диаметром $\sim 10$ см для получения двух ФЭП площадью $\sim 30 \mathrm{~cm}^{2}$ каждый.

Выполнено моделирование распределения толщины гальванического осадка по площади гетероструктуры, проведены исследования технологии формирования омических контактов, изучены особенности электрохимического осаждения контактных материалов при вертикальном и горизонтальном расположении гетероструктуры и анода, проведена оптимизация режимов электрохимического наращивания контактной системы $\mathrm{Ag} / \mathrm{Au}$ с целью улучшения монолитности контактов и увеличения равномерности толщины контактных материалов.

\section{2. Этапы формирование омических контактов}

Создание омических контактов осуществляется в несколько этапов. На фронтальной поверхности гетероструктуры формируется маска, состоящая из слоя фоторезиста, задающего топологию изготавливаемого прибора. Проводится напыление контактной системы $n$-типа проводимости, например, на основе слоев $\mathrm{Au}(\mathrm{Ge}) / \mathrm{Ni} / \mathrm{Au}$, и $p$-типа проводимости, например, на основе слоев $\mathrm{Ag}(\mathrm{Mn}) / \mathrm{Ni} / \mathrm{Au}, \mathrm{Cr} / \mathrm{Au}$. Выполняется термический отжиг контактных систем для снижения удельного переходного сопротивления. Выполняется электрохимическое наращивание контактов для увеличения их толщины и, соответственно, электрической проводимости, а также для последующего монтажа ФЭП. Наиболее широко используемые материалы для наращивания контактов это серебро и золото, обладающие высокой электропроводностью $\left(\mathrm{Ag}-0.015-0.016 \mathrm{OM} \cdot \mathrm{MM}^{2} / \mathrm{M} ; \mathrm{Au}-\right.$ $\left.0.023 \mathrm{OM} \cdot \mathrm{Mм}^{2} / \mathrm{M}\right)$. Электрохимическое осаждение контактных материалов осуществляется через защитную однослойную или двухслойную маску, состоящую из слоя 


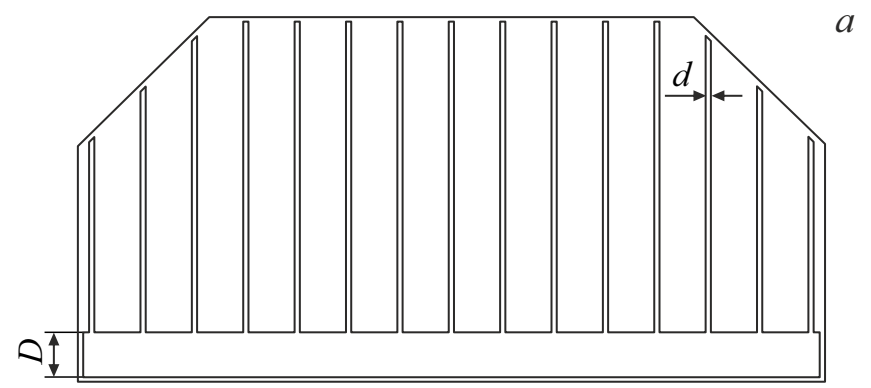

b

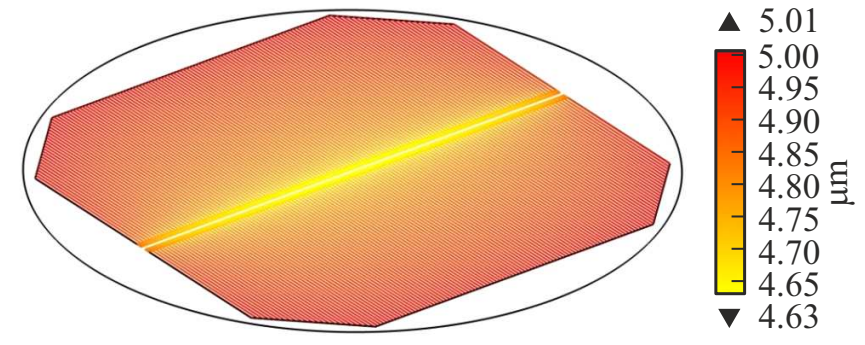

Рис. 1. Схема контактной сетки „космического“ ФЭП $4 \times 8 \mathrm{~cm}(a)$, результат моделирования толщины контактной сетки по площади гетероструктуры $(b)$. (Цветной вариант рисунка представлен в электронной версии статьи).

фоторезиста и подслоя диэлектрического материала, наносимого для улучшения точности задания топологии ФЭП и защиты фоточувствительной поверхности.

\section{3. Моделирование гальванического осаждения слоев серебра}

Основным материалом, используемым для электрохимического наращивания омических контактов ФЭП, является серебро. Для анализа равномерности толщины гальванического осадка по площади гетероструктуры диаметром до $10 \mathrm{~cm}$ было проведено моделирование процесса осаждения серебра для стандартной топологии „космического“ ФЭП размером $4 \times 8$ см (рис. $1, a)$. Локальная скорость осаждения металла прямо пропорциональна локальной плотности тока, которая в свою очередь пропорциональна локальной электропроводности системы ,анод-электролит-контакт-гетероструктура“. Расчет распределения плотности тока на поверхности гетероструктуры осуществлялся с учетом омических потерь при протекании тока по областям топологии контактов с различной площадью поперечного сечения. При расчетах было сделано допущение, что электролит однороден по составу во всем объеме и его свойства не изменяются в течение процесса осаждения.

При проведении постростовой обработки гетероструктур на пластине проводится формирование двух чипов ФЭП, при этом контактная площадка шириной $D$ (рис. $1, a)$ каждого чипа проходит через центр пластины, а контактные шины шириной $d$ располагаются перпендикулярно контактной площадке. При моделировании электрохимического наращивания омических контактов учитывалось неравномерное распределение плотности тока из-за различия в ширине контактной площадки и контактных шин и из-за влияния „краевого“ эффекта увеличения плотности тока от центра к периферийным участкам пластины, что ведет к снижению толщины слоев контактных площадок в центральной области пластины (светлая желтая область) и к увеличению толщины слоев в контактных шинах по периметру пластины (темная красная область) (рис. 1, $b$ ). При моделировании контактной сетки космического ФЭП $4 \times 8$ см с толщиной контактных шин $\sim 5$ мкм значения равномерности толщины контактов составили $\sim 95 \%$.

\section{4. Гальваническое осаждение контактной системы $\mathrm{Ag} / \mathrm{Au}$}

Широко используемым электролитом для осаждения серебра, обладающим большим сроком эксплуатации
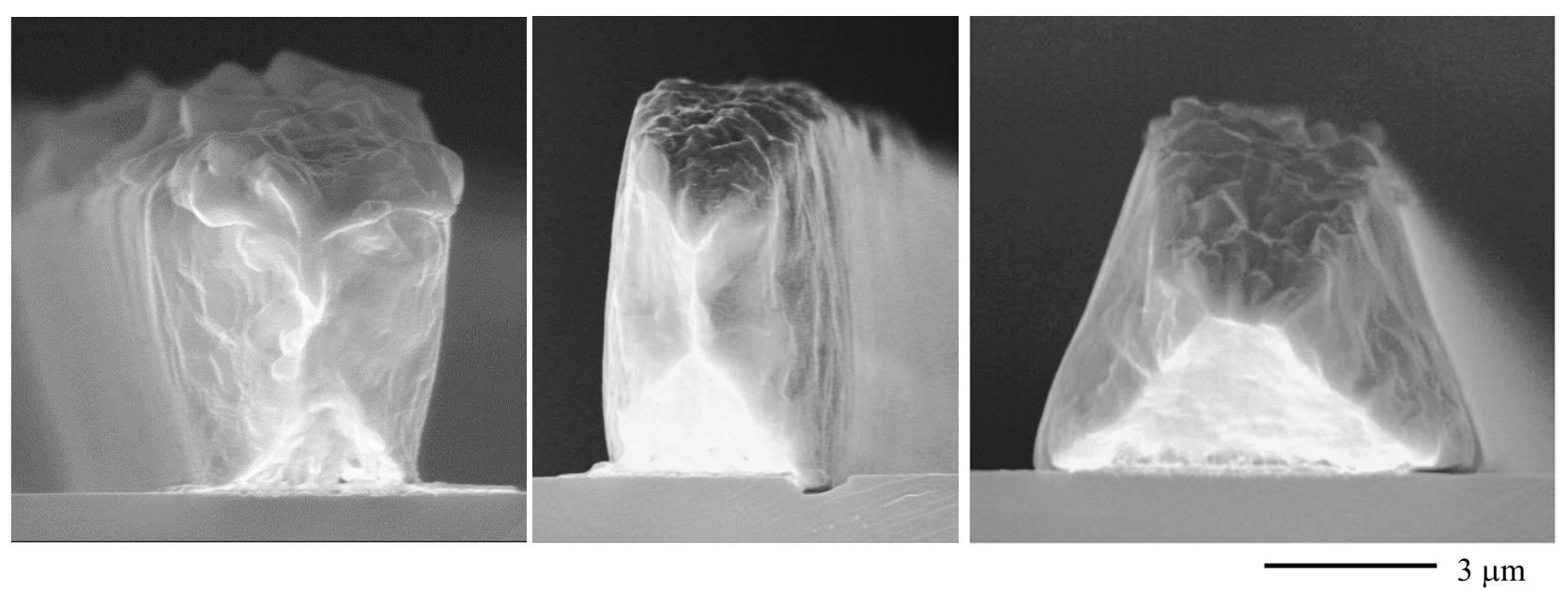

Рис. 2. Фотографии, выполненные на растровом электронном микроскопе, контактных шин, полученных путем электрохимического осаждения серебра из железосинеродистого электролита серебрения с разным профилем наклона боковой стенки. 


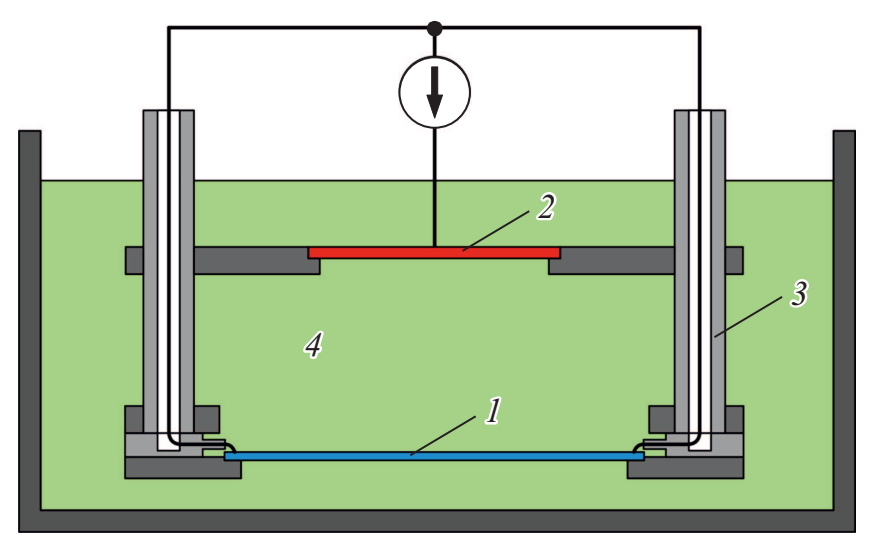

Рис. 3. Схема устройства для электрохимического наращивания омических контактов ФЭП: 1 - гетероструктура, 2 - анод, 3 - держатель анода и гетероструктуры, 4 - электролит.

(более 1 года) и не требующим особых условий хранения, является железосинеродистый электролит серебрения. Для защиты серебряных контактов от воздействия факторов окружающей среды, а также для проведения дальнейшего монтажа ФЭП была разработана технология осаждения защитного слоя золота на поверхность серебра с использованием цианистого электролита золочения.

Электрохимическое осаждение серебра из железосинеродистого электролита возможно при низкой температуре $18-25^{\circ} \mathrm{C}$, что облегчает процесс формирования защитной маски и позволяет модифицировать профиль контактных шин от вертикального до наклонного (рис. 2). Для увеличения плотности и монолитности осадка, а также для улучшения адгезии Ag к поверхности гетероструктуры проведена разработка двухэтапного процесса осаждения. Экспериментально было установлено, что наилучшие результаты достигаются при следующих режимах осаждения: на стадии зародышеобра- зования плотность тока составляет $0.005-0.01 \mathrm{MA} / \mathrm{MM}^{2}$, а на основном этапе роста плотность тока увеличивается до $0.04-0.05 \mathrm{MA} / \mathrm{MM}^{2}$. Осаждение серебра в этих режимах осуществляется в строгом соответствии с топологией контактной сетки, что позволяет проводить формирование профиля контактных шин с высокой точностью.

Известны различные системы для электрохимического наращивания омических контактов при вертикальном $[6,9]$ или горизонтальном [10] расположении гетероструктуры и анода в электролите.

При проведении исследования равномерности осаждения серебра при вертикальном расположении гетероструктуры и анода в электролите было обнаружено различие скоростей роста в разных областях гетероструктуры, что может быть связано со свойствами электролита и с различной скоростью отвода продуктов реакции. Равномерность роста контактной сетки при толщине шин $\sim 5$ мкм составила $\sim 85-90 \%$, что существенно ниже результатов моделирования процесса.

Было проведено сравнительное исследование при горизонтальном варианте расположения гетероструктуры и анода в электролите. Для этого было разработано устройство электрохимического осаждения контактных материалов при горизонтальном расположении гетероструктуры в нижней области электрохимической ванны и анода в верхней области над гетероструктурой (рис. 3) [11]. Основной проблемой при проведении процесса с данным расположением является образование в электролите пузырьков при выделении водорода в ходе протекания электрохимических реакций, которые, поднимаясь на поверхность электролита, скапливаются на поверхности анода и препятствуют равномерному протеканию процесса осаждения. Для предотвращения скапливания пузырьков на аноде в процессе осаждения к держателю анода был прикреплен мотор, осуществляющий периодическую вибрацию анода, что обеспечило равномерное протекание процесса электрохимического осаждения.
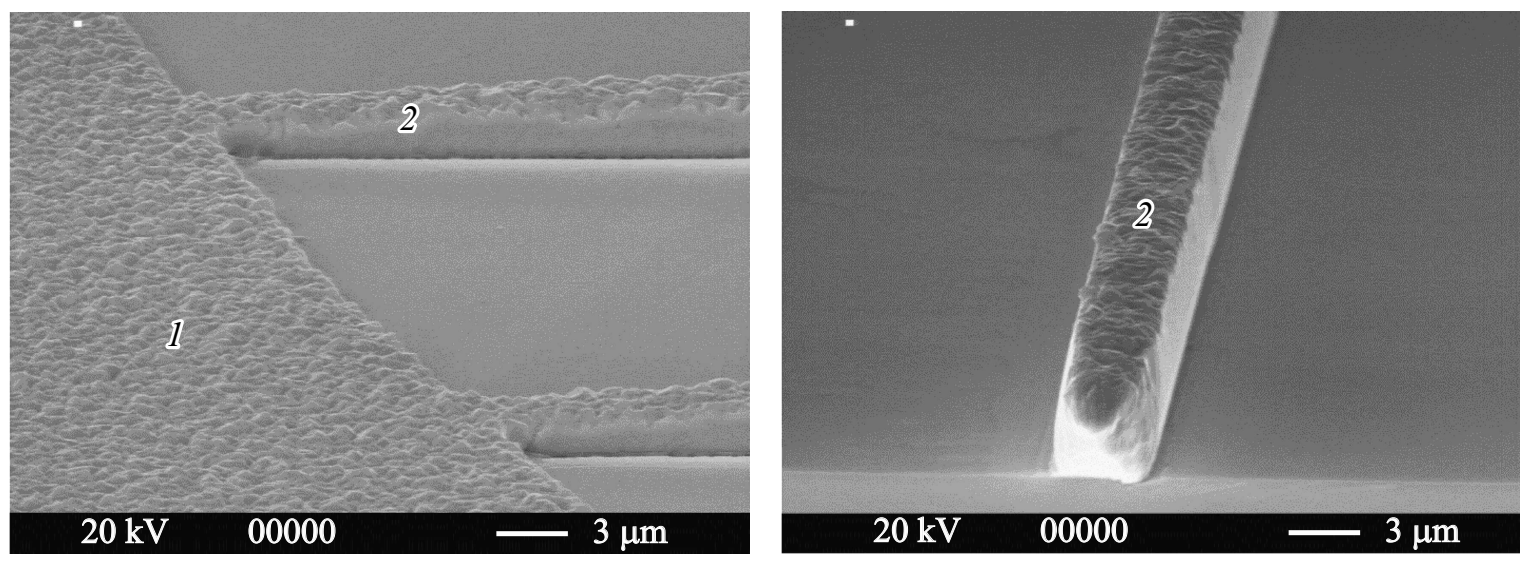

Рис. 4. Фотографии, выполненные на растровом электронном микроскопе, контактной сетки, полученной путем электрохимического осаждения серебра из железосинеродистого электролита серебрения: 1 - контактная площадка, 2 - контактная шина. 
С использованием разработанных режимов и устройства горизонтального осаждения было проведено наращивание контактной системы $\mathrm{Ag} / \mathrm{Au}$ по маске фоторезиста с вертикальным профилем боковых стенок (рис. 4). Равномерность скорости роста контактной сетки при толщине шин $\sim 5$ мкм составила $\sim 95 \%$, что соответствует результатам моделирования процесса.

Преимуществом наращивания омических контактов с использованием контактной системы $\mathrm{Ag} / \mathrm{Au}$ являются низкая стоимость технологического процесса, высокая надежность используемого серебряного электролита и высокое качество осажденного серебра, характеризующегося незначительной шероховатостью поверхности и высокой монолитностью. Эти параметры осажденных $\mathrm{Ag} / \mathrm{Au}$ слоев обеспечивают увеличение электропроводности контактной структуры и, соответственно, энергоэффективности ФЭП.

\section{5. Заключение}

Проведено моделирование и исследование процесса электрохимического наращивания контактной системы на основе серебра и золота при вертикальном и горизонтальном расположении гетероструктуры и анода в электролите. Разработана технология формирования монолитных омических контактов с высокой электропроводностью и высокой адгезией к поверхности гетероструктуры при равномерности толщины контактного материала на основе серебра $\sim 95 \%$ на площади гетероструктуры диаметром до $10 \mathrm{~cm}$ при горизонтальном варианте расположения пластины и анода.

\section{Конфликт интересов}

Авторы заявляют, что у них нет конфликта интересов.

\section{Список литературы}

[1] Zh.I. Alferov, V.M. Andreev, V.D. Rumyantsev. III-V Hetestructures in Photovoltaics. In: Concentrator Photovoltaics, ed. by A. Luque, V. Andreev. Springer Ser. in Optical Sciences (Springer, Berlin-Heidelberg), 130, 25 (2007). DOI: 10.1007/978-3-540-68798-6_2

[2] G.C. Schwartz, K.V. Srikrishnan. Hadbook of semiconductor technology (Boca Raton, Taylor \& Francis Group, 2006).

[3] Zh.I. Alferov, V.M. Andreev, M.Z. Shvarts. III-V Solar Cells and Concentrator Arrays. In: High Efficient LowCos Photovoltaics, ed. by V. Petrova-Koch, R. Hezel, A. Goetzberger. Springer Ser. in Optical Sciences, 140, 133 (2020). DOI: 10.1007/978-3-030-22864-4_8

[4] Handbook of Concentrator Photovoltaic Technology, ed. by Carlos Algora, Rey-Stole Ignacio (John Willey \& Sons, Ltd, 2016).

[5] H. Cotal, Ch. Fetzer, J. Boisvert, G. Kinsey, R. King, P. Hebert, H. Yoon, N. Karam. Energy Environ. Sci., 2, 174 (2009). DOI: 10.1039/B809257E
[6] А.В. Малевская, В.П. Хвостиков, Ф.Ю. Солдатенков, О.А. Хвостикова, А.С. Власов, В.М. Андреев. Письма ЖТФ, 45 (1), 12 (2019). DOI: 10.21883/FTP.2022.03.52127.9774

[7] У. Моро. Микролитография (М., Мир, 1990).

[8] Е.В. Слыщенко, А.А. Наумова, А.А. Лебедев, М.А. Генали, Н.Т. Вагапова, Б.В. Жалнин. Сибирский журнал науки и техники, 19 (2), 308 (2018).

[9] A.V. Malevskaya, D.A. Malevski, N.D. Il'inskaya. J. Phys.: Conf. Ser., 690, 012039 (2016). DOI:10.1088/1742-6596/690/1/012039

[10] Б.Н. Самсоненко, Н.С. Разувайло, Л.В. Вельганенко. Патент RU2357326 (2009).

[11] А.В. Малевская, Н.Д. Ильинская, Д.А. Малевский, П.В. Покровский. Патент RU2756198 (2021).

\section{Electrochemical deposition of contact materials in postgrowth technology of photovoltaic converters}

\author{
A.V. Malevskaya, N.D. Il'inskaya, D.A. Malevskii, \\ P.V. Pokrovskii \\ loffe Intitute, \\ 194021 St. Petersburg, Russia
}

\begin{abstract}
Investigations and modeling of ohmic contacts electrochemical deposition process in postgrowth technology of photovoltaic converters fabrication have been carried out. The technology of Ag/Au contact system galvanic deposition at vertical and horizontal position of heterostructure and anode in the electrolyte has been developed. The increase of contact system deposition uniformity up to $\sim 95 \%$ at the thickness of contact bus-bars $\sim 5 \mu \mathrm{m}$ on the heterostructure area with 4 inch diameter has been archived.
\end{abstract}

